\title{
Transpiração e crescimento foliar de plantas de mandioca em resposta ao deficit hídrico no solo
}

\author{
Isabel Lago(1), Nereu Augusto Streck(1), Dilson Antônio Bisognin ${ }^{(1)}$, André Trevisan de Souza ${ }^{(1)}$ \\ e Michel Rocha da Silva(1)
}

(1)Universidade Federal de Santa Maria, Centro de Ciências Rurais, Departamento de Fitotecnia, CEP 97105-900 Santa Maria, RS.
E-mail: isabel.lago@ufpel.edu.br, nstreck1@smail.ufsm.br, dilson@ccr.ufsm.br, andretrevisandesouza@yahoo.com.br, michelrs@live.com

Resumo - O objetivo deste trabalho foi determinar a transpiração e o crescimento foliar de duas cultivares de mandioca, em resposta ao conteúdo de água disponível no solo representado pela fração de água transpirável no solo (FATS). Foram realizados dois experimentos, em vasos de $8 \mathrm{~L}$, com as cultivares Fécula Branca e Fepagro RS 13. O plantio foi feito em 11/9/2009 e 8/9/2010, em delineamento experimental inteiramente casualizado. A água disponível, a transpiração e o crescimento foliar foram medidos diariamente, em cada experimento, durante o período de imposição da deficiência hídrica. A FATS crítica, em que a transpiração começa a ser reduzida, foi de 0,45 para 'Fécula Branca' e 0,50 para 'Fepagro RS 13'. A redução do crescimento foliar começou quando a FATS atingiu 0,51 para 'Fécula Branca' e 0,49 para 'Fepagro RS 13'. A FATS crítica para transpiração e crescimento foliar difere em condições de atmosfera com baixa e com alta demanda evaporativa do ar, conforme a cultivar de mandioca utilizada.

Termos para indexação: Manihot esculenta, deficit hídrico, fechamento estomático, fração de água transpirável, umidade crítica no solo.

\section{Transpiration and leaf growth of cassava plants as a response to soil water deficit}

\begin{abstract}
The objective of this work was to determine the transpiration and leaf growth of two cassava cultivars, as a response to the available soil water content represented by the fraction of transpirable soil water (FTSW). Two experiments were carried out in 8-L pots with the cassava cultivars Fécula Branca and Fepagro RS 13. Planting was done on $9 / 11 / 2009$ and on $9 / 8 / 2010$, in a completely randomized design. The available soil water, the transpiration and the leaf growth were measured on a daily basis, in each experiment, during the period of soil drying. The threshold FTSW, at which the transpiration begins to reduce, was 0.45 for 'Fécula Branca' and 0.50 for 'Fepagro RS 13'. Reduction of leaf growth started at $0.51 \mathrm{FTSW}$ for 'Fécula Branca' and at 0.49 for 'Fepagro RS 13'. Threshold FTSW for transpiration and for leaf growth differs in atmosphere conditions with high and low atmospheric demand, depending on the utilized cassava cultivar.

Index terms: Manihot esculenta, water deficit, stomata closure, fraction of transpirable water, threshold soil moisture.
\end{abstract}

\section{Introdução}

Os processos vegetais que dependem do aumento do volume celular são os mais sensíveis ao deficit hídrico. A área foliar depende da expansão celular, e as trocas gasosas na folha (transpiração e assimilação de $\mathrm{CO}_{2}$ ) dependem do volume das células-guarda (Moreno-Fonceca, 2009; Taiz \& Zeiger, 2009). Uma inibição desses processos pode causar uma considerável redução na produtividade e qualidade da produção. Um conceito muito utilizado na avaliação das respostas das plantas ao deficit hídrico é o conceito da fração de água transpirável no solo (FATS). Neste conceito, assume-se que a quantidade de água do solo utilizada pela planta para a transpiração varia de acordo com o conteúdo de água no solo (Sinclair \& Ludlow, 1986).

A FATS em que se inicia o fechamento estomático (FATS crítica) é um parâmetro que pode ser usado para identificar genótipos mais tolerantes ao deficit hídrico (Jyostna Devi et al., 2009). Uma outra utilização da FATS crítica é em modelos de simulação de culturas (Alberto et al., 2006). Sinclair \& Ludlow (1986) obtiveram valores de FATS crítica de 0,40 para as culturas do feijão-mungo (Vigna mungo L. Hepper),

Pesq. agropec. bras., Brasília, v.46, n.11, p.1415-1423, nov. 2011 
guandu (Cajanus cajan L.) e soja (Glycine max L. Merrill), e 0,30 para o feijão-caupi (Vigna unguiculata L. Walp.). Amir \& Sinclair (1991), em trabalho com modelagem do crescimento e rendimento de trigo (Triticum aestivum L.) de primavera, utilizaram FATS crítica de 0,30 para a transpiração e 0,40 para o crescimento foliar. Em milho (Zea mays L.), Muchow \& Sinclair (1991) obtiveram valores de FATS crítica de 0,30 para transpiração e crescimento foliar. Ray \& Sinclair (1997) estudaram oito híbridos de milho e encontraram valores de FATS crítica entre 0,36 e 0,60. Em arroz (Oryza sativa L.), Davatgar et al. (2009) obtiveram valores de FATS crítica de 0,46 para transpiração e 0,44 para crescimento foliar. Em amendoim (Arachis hypogaea L.), Jyostna Devi et al. (2009) obtiveram valores de FATS crítica de 0,22 a 0,71 .

A demanda evaporativa da atmosfera pode afetar os valores de FATS crítica. Ray et al. (2002) levantaram a hipótese de que, em condição de alta demanda evaporativa da atmosfera (alto deficit de pressão de vapor do ar, DPV), as plantas apresentam taxa de transpiração alta, o que requer maior fluxo de água do solo para suprir a transpiração. Esse fato poderia levar à limitação do fluxo transpiratório com um conteúdo de água maior no solo, ou seja, poderia resultar em maiores valores de FATS crítica, mas essa hipótese não se confirmou em seu estudo com dois híbridos de milho, que não apresentaram variação significativa nos valores de FATS crítica entre os tratamentos de DPV $(11,20,29$ e $36 \mathrm{hPa})$. No entanto, alguns trabalhos indicam que a transpiração aumenta com o aumento do DPV, e que as respostas variam entre espécies e entre genótipos da mesma espécie (Fletcher et al., 2007; Sinclair et al., 2008; Wherley \& Sinclair, 2009; Gholipoor et al., 2010; Kholová et al., 2010).

A mandioca é considerada um dos principais alimentos energéticos, especialmente nos países em desenvolvimento, onde é cultivada em pequenas áreas e com baixo nível tecnológico (Alves, 2002). O Brasil é responsável por aproximadamente $11 \%$ da produção mundial de mandioca e ocupa a posição de terceiro maior produtor mundial, atrás da Nigéria e da Tailândia (Food and Agriculture Organization of the United Nations, 2011). No Rio Grande do Sul (RS), o terceiro maior produtor de mandioca do Brasil, essa cultura é cultivada principalmente em pequenas propriedades rurais da região norte e Depressão Central do Estado.
Em condições de deficit de água no solo ou de alta demanda evaporativa da atmosfera, as plantas de mandioca apresentam controle estomático bastante eficiente (El-Sharkawy et al., 1989; Alves \& Setter, 2000, 2004; El-Sharkawy, 2007). Contudo, a redução da abertura estomática pode limitar a taxa de difusão de $\mathrm{CO}_{2}$ para o interior da folha, com efeitos diretos sobre a fotossíntese e o crescimento (Alves, 2002; El-Sharkawy, 2007). Outra característica de adaptação ao deficit hídrico, em plantas de mandioca, é a redução da área foliar pela perda das folhas basais mais velhas (El-Sharkawy, 2007). Variedades de mandioca podem diferir quanto à tolerância ao deficit hídrico, o que abre oportunidade para seleção genética quanto a esse caráter. Não foram encontrados, na literatura, trabalhos sobre a resposta da transpiração e do crescimento foliar à FATS, para a cultura da mandioca.

O objetivo deste trabalho foi determinar a transpiração e o crescimento foliar de duas cultivares de mandioca, em resposta ao conteúdo de água disponível no solo, representado pela fração de água transpirável no solo.

\section{Material e Métodos}

Foram realizados dois experimentos com a cultura da mandioca, com plantio em 11/9/2009 (Man1) e 8/9/2010 (Man2), em abrigo telado de $150 \mathrm{~m}^{2}$, coberto com polietileno de baixa densidade, de $200 \mu \mathrm{m}$ de espessura, e paredes laterais revestidas com tela antiafídeos, na área experimental do Departamento de Fitotecnia, da Universidade Federal de Santa Maria

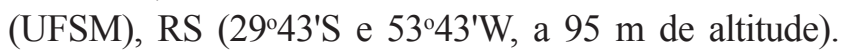
As cultivares de mandioca utilizadas foram Fepagro RS 13 e Fécula Branca, a primeira recomendada para o consumo humano e para uso forrageiro (Azevedo et al., 2006), e a segunda para a indústria.

Em cada experimento, utilizou-se o delineamento experimental inteiramente casualizado, em esquema bifatorial, tendo como fator $\mathrm{A}$ as duas cultivares de mandioca, e como fator $\mathrm{B}$, dois regimes hídricos. Os tratamentos considerados foram: $\mathrm{T} 1$, sem deficit hídrico (com irrigação), e T2, com deficit hídrico (sem irrigação). Os dois experimentos contaram com dez repetições para cada tratamento, em que a parcela experimental correspondeu a um vaso de $8 \mathrm{~L}$ com uma planta, o que totalizou 40 plantas por experimento. Foi utilizado solo da classe textural franco (horizonte A), pertencente à unidade de mapeamento Santa Maria, 
classificado como Argissolo Bruno-Acinzentado alítico típico (Santos et al., 2006). Em cada experimento, os vasos foram dispostos sobre uma bancada de $70 \mathrm{~cm}$ de altura em relação ao piso do abrigo telado.

Para o plantio, foram selecionadas manivas com diâmetro entre $1 \mathrm{e} 1,5 \mathrm{~cm}$, as quais foram cortadas em pedaços (toletes) de aproximadamente $12 \mathrm{~cm}$, tendo sido plantado um tolete por vaso. Foi selecionada apenas uma brotação que originou a planta usada no experimento. No Man1, as emergências (50\% das plantas) ocorreram em 10/10/2009 e 6/10/2009 para as cultivares Fécula Branca e Fepagro RS 13, respectivamente, e, no Man2, em 25/9/2010, para as duas cultivares.

As datas de início da imposição do deficit hídrico foram 19/11/2009 (Man1) e 5/11/2010 (Man2), quando as plantas estavam, em média, com 13 (Fécula Branca) e 15 folhas (Fepagro RS 13), no Man1, e 14 folhas, em ambas as cultivares, no Man2. O deficit hídrico foi aplicado nesse estágio para que o início da acumulação de amido ocorresse até o final do experimento, o que realmente aconteceu, pois, no último dia do experimento, as plantas sem deficit hídrico já tinham raízes tuberosas. $\mathrm{O}$ início da acumulação de amido ocorre com aproximadamente 21 folhas visíveis na haste principal, na 'Fepagro RS 13', o que acontece, aproximadamente, entre 70 e 80 dias após o plantio (Schons et al., 2007). Esse estágio é importante, pois marca o início da translocação dos fotoassimilados para os órgãos de reserva da espécie, o que modifica a relação fonte/dreno na planta (Matthews \& Hunt, 1994), e é nesse período que a ocorrência de deficit hídrico é mais prejudicial (Alves, 2002).

Em cada experimento, das 20 repetições de cada cultivar, 10 foram usadas como testemunha (T1), nas quais não foi aplicada a deficiência hídrica. Nas outras 10 repetições, foi aplicada a deficiência hídrica (T2). Em cada experimento, também foram utilizados seis vasos, que foram preenchidos com solo no dia do plantio, mas que permaneceram sem plantas.

A aplicação do deficit hídrico seguiu a metodologia proposta por Sinclair \& Ludlow (1986). Esta metodologia utiliza o conceito da fração de água transpirável no solo (FATS) para avaliar as respostas das plantas ao deficit hídrico, que considera dois estágios de deficiência hídrica: estágio I, quando a água está disponível livremente no solo, a planta não tem deficiência hídrica, e a condutância estomática e transpiração são máximas; estágio II, quando a água disponível no solo diminui, e a planta diminui a condutância estomática e a transpiração, a fim de manter o balanço hídrico e a turgescência celular (evitando perda excessiva de água).

Para iniciar cada experimento, todos os vasos foram saturados com água e deixados drenar por 20 a 24 horas, para atingirem a capacidade de campo (Sinclair \& Ludlow, 1986; Ray \& Sinclair, 1997). Depois de saturados, todos os vasos foram cobertos com um filme de plástico branco, para minimizar a perda de água pela evaporação do solo. Completadas as 20 a 24 horas após a saturação, foi determinada a massa inicial de cada vaso e, a partir de então, foi aplicada a deficiência hídrica nos vasos do T2, que não foram mais irrigados até o final do experimento (Sinclair \& Ludlow, 1986).

Diariamente, ao final da tarde, foi determinada a massa de todos os vasos, em uma balança eletrônica com capacidade de $50,0 \mathrm{~kg}$ e precisão de $0,005 \mathrm{~kg}$. Logo após a pesagem, cada vaso do T1 foi irrigado com a quantidade de água perdida pela transpiração da planta, determinada pela diferença entre a massa do vaso no dia e a massa inicial. Os seis vasos sem planta também foram pesados diariamente e, em três deles, foi reposto o volume de água perdido por evaporação no período. O objetivo foi contabilizar a evaporação do solo, ocorrida mesmo com os vasos cobertos pelo filme de plástico. Os valores médios diários de evaporação foram subtraídos dos valores de transpiração diária das plantas, antes do cálculo da transpiração relativa.

Os dados foram analisados com base na comparação entre os valores de transpiração relativa (TR) e os valores de fração de água transpirável no solo (FATS) para cada vaso. A TR foi calculada pela equação (Sinclair \& Ludlow, 1986): TR = perda diária de água pelas plantas do T2 (cada vaso)/ média da perda diária de água das plantas do T1, em que a perda diária de água pelas plantas do T2 foi obtida pela diferença entre a massa de cada vaso no dia e a massa do mesmo vaso no dia anterior. A perda diária de água pelas plantas do T1 foi obtida pela diferença entre a massa de cada vaso, no dia, e a massa do mesmo vaso no dia do início do experimento (massa inicial). Na equação, foi utilizada a média da perda diária das dez plantas de cada cultivar.

Cada experimento foi iniciado 20 a 24 horas após a saturação dos vasos e foi encerrado quando todas as plantas do $\mathrm{T} 2$ apresentavam $\mathrm{TR} \leq 0,1$. A massa final 
foi considerada a massa do vaso quando a $\mathrm{TR} \leq 0,1$ foi atingida. Foi imposto o limite de 0,1 (10\%), porque abaixo dessa taxa de transpiração os estômatos estão fechados, e a perda de água ocorre apenas em razão da condutância epidérmica, que é o estágio III da transpiração (Sinclair \& Ludlow, 1986). O período de deficit hídrico durou 15 dias para 'Fepagro RS 13' e 25 dias para 'Fécula Branca', no Man1, e 20 dias para as duas cultivares no Man2.

Após o término de cada experimento, foi calculada a FATS para cada vaso do T2, em cada dia, do último para o primeiro dia de deficit hídrico. A FATS foi calculada pela equação (Sinclair \& Ludlow, 1986) FATS = (massa de cada vaso em cada dia - massa final)/(massa inicial de cada vaso - massa final).

A área foliar (AF) total de cada planta foi determinada diariamente, a partir do início da aplicação do deficit hídrico até o final de cada experimento. Para isso, mediu-se o comprimento do maior lóbulo, e a AF de cada folha de mandioca foi calculada pelas equações $\mathrm{AF}=3,2792 \mathrm{x}+0,1607 \mathrm{x}^{2}+0,0402 \mathrm{x}^{3}$, para 'Fepagro RS 13' (Schons et al., 2009), e AF $=15,672-6,5575 x$ $+1,5839 x^{2}-0,0329 x^{3}$, para 'Fécula Branca', em que AF é a área da folha $\left(\mathrm{cm}^{2}\right)$ e $\mathrm{x}$ é o comprimento do maior lóbulo. Para determinar a equação para calcular a área foliar de 'Fécula Branca' coletaram-se 65 folhas, com comprimento do maior lóbulo entre 3 e $14 \mathrm{~cm}$, de plantas não usadas no experimento. Em cada uma dessas folhas, mediu-se o comprimento do maior lóbulo (x), e a AF foi estimada pelo método das fotocópias ou dos contornos foliares. A equação polinomial de $3 \circ$ grau foi a que melhor ajustou-se aos dados $\left(\mathrm{R}^{2}=0,9371\right) \mathrm{e}$, por isso, foi selecionada para estimar a área foliar de 'Fécula Branca' no presente trabalho.

A AF total diária de cada planta foi calculada pelo somatório da AF de todas as folhas individuais da planta. Com esses dados de AF total diária, foi calculado o crescimento foliar relativo (CFR) diário, para cada cultivar, pela equação $\mathrm{CFR}=$ aumento de $\mathrm{AF}$ total pelas plantas do T2 (cada planta)/aumento médio de AF total pelas plantas do T1, em que o aumento de AF total pelas plantas de T1 e T2 (diário) é calculado pela diferença entre a AF total de cada planta, no dia, e a AF total da mesma planta no dia anterior.

As temperaturas mínima e máxima diárias do ar foram medidas, durante cada experimento, com um termômetro de mínima de álcool e um termômetro de máxima de mercúrio, respectivamente, instalados dentro de um abrigo meteorológico de madeira pintada de branco, posicionado no centro da bancada. Também foram usados os dados do psicrômetro (temperatura do bulbo seco e do bulbo úmido), às $15 \mathrm{~h}$, e o brilho solar diário na estação meteorológica convencional, pertencente ao 8o Distrito de Meteorologia, localizada a aproximadamente $300 \mathrm{~m}$ do abrigo telado, onde foram conduzidos os experimentos. Com esses dados, calculou-se o deficit de pressão de vapor do ar (DPV) às $15 \mathrm{~h}$ (próximo ao DPV máximo diário) e a densidade de fluxo de radiação solar global diária incidente. Considerou-se uma transmissividade da cobertura de plástico de $80 \%$, para o cálculo da radiação solar global diária incidente sobre as plantas.

Para detectar possíveis diferenças de FATS crítica, entre diferentes condições de demanda evaporativa da atmosfera, os dados de TR e CFR foram separados em dias com baixa demanda evaporativa da atmosfera (valores de DPV menores do que $15 \mathrm{hPa}$ ) e em dias com alta demanda evaporativa da atmosfera (valores de DPV maiores do que $15 \mathrm{hPa}$ ) (Kiniry et al., 1998), que foram analisados separadamente.

As variáveis TR e CFR foram submetidas a duas normalizações. A primeira normalização (TR1 e CFR1) foi realizada para ficar entre valores de 0 a 1 , e a segunda normalização (TR2 e CFR2) para reduzir as variações entre plantas, causadas por diferenças no tamanho das plantas e nas condições microambientais. Para a segunda normalização, encontrou-se uma FATS acima da qual a TR e o CFR foram constantes em todas as plantas, no caso com um valor de 0,55. Após isso, calculou-se, para cada planta, a média dos valores de TR e CFR com FATS igual ou maior que 0,55 , e todas as estimativas iniciais de TR e CFR foram divididas por essas médias (Sinclair \& Ludlow, 1986; Ray \& Sinclair, 1997). A segunda normalização foi calculada pelas equações TR2 $=$ TR1/TR1 média dos dias com FATS acima de 0,55 e CFR2 $=$ CFR1/CFR1 média dos dias com FATS acima de 0,55.

Os dados de TR e CFR, após passarem pela segunda normalização, foram plotados em função da FATS e foi ajustada a eles a equação logística do tipo

$$
\mathrm{Y}=1 /\{1+\exp [-\mathrm{a}(\mathrm{X}-\mathrm{b})]\},
$$

em que: Y é a variável dependente (TR ou CFR); X é a FATS; e a e b são coeficientes empíricos (Sinclair \& Ludlow, 1986; Ray \& Sinclair, 1997) estimados por análise de regressão não linear com uso do SAS (SAS Institute, 2001). Os valores de FATS crítica para TR e 
para CFR foram estimados pela equação logística como o valor da FATS, quando a TR e o CFR são 0,95.

\section{Resultados e Discussão}

Os valores de temperatura média do ar apresentaram pouca variação entre os dois experimentos, tendo sido de $25,8^{\circ} \mathrm{C}$ no Man 1 , e $25,0^{\circ} \mathrm{C}$ no Man2 (Figura 1). Apesar de os valores de temperatura média do ar terem sido semelhantes, as demais variáveis caracterizam condições meteorológicas distintas entre os experimentos. As médias das temperaturas mínima e máxima diárias do ar foram 20,1 e $31,5^{\circ} \mathrm{C}$, no experimento Man1, e 16,1 e $33,9^{\circ} \mathrm{C}$, no Man2, respectivamente. A densidade de fluxo de radiação solar global diária incidente e o DPV foram mais elevados no Man2 (15,2 $\mathrm{MJ} \mathrm{m}^{-2}$ por dia e 19,5 hPa, respectivamente) do que no Man $1\left(12,4 \mathrm{MJ} \mathrm{m}^{-2}\right.$ por dia e $10,0 \mathrm{hPa}$, respectivamente). O número de dias em que a demanda evaporativa da atmosfera foi alta (DPV às $15 \mathrm{~h}$ maior do que $15 \mathrm{hPa}$ ) foi maior no experimento Man2 $(16 / 22=72 \%)$ do que no Man1 $(7 / 26=27 \%)$ (Figura 1 C). Com base nestes dados, pode-se considerar que o experimento Man2 ocorreu em um período com maior demanda evaporativa da atmosfera, em comparação ao Man1. Essas condições distintas foram causadas por primavera bastante chuvosa em 2009 e bastante seca em 2010, o que, provavelmente foi resultado da ocorrência do fenômeno El Niño na primeira e La Niña na segunda.

A FATS crítica, que começa a afetar a transpiração, indicativa do início do fechamento estomático, foi de 0,45 para 'Fécula Branca' e 0,50 para 'Fepagro RS 13' (Figura 2). Na média dos dois experimentos, o fechamento estomático em resposta ao deficit hídrico na 'Fepagro RS 13' ocorreu com maior umidade no solo do que para 'Fécula Branca' o que, segundo Muchow \& Sinclair (1991), pode ser um meio de a planta conservar a água no solo e suportar uma deficiência hídrica mais prolongada. Porém, ao se analisar separadamente os dias com baixa (DPV do ar às $15 \mathrm{~h}$ menor do que $15 \mathrm{hPa}$ ) e alta (DPV do ar às $15 \mathrm{~h}$ maior do que $15 \mathrm{hPa}$ ) demanda evaporativa da atmosfera, observa-se que, em condição de baixa demanda, 'Fécula Branca' apresenta FATS crítica maior $(0,46)$ do que 'Fepagro RS 13' $(0,42)$. Em condição de alta demanda evaporativa da atmosfera, a FATS crítica é maior para 'Fepagro RS 13' $(0,50)$ do que para 'Fécula Branca' $(0,44)$. Isso indica que, possivelmente, a cultivar Fepagro RS 13 apresenta controle estomático mais eficiente em condição de alta demanda atmosférica.

Pode-se inferir que a cultivar Fécula Branca não tem controle estomático tão eficiente e utiliza outro
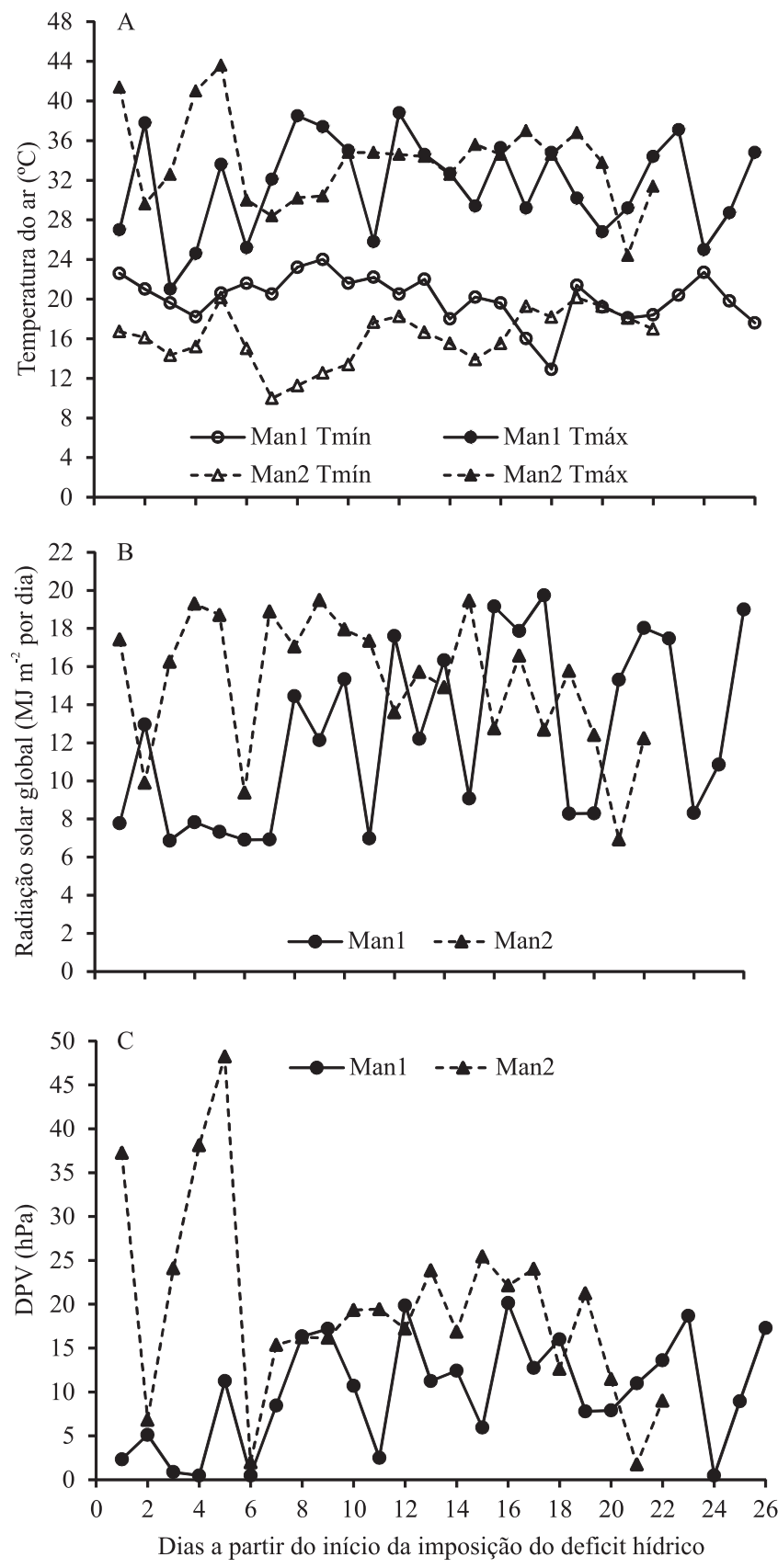

Figura 1. Temperaturas mínima (Tmín) e máxima (Tmáx) diárias do ar (A) e densidade de fluxo de radiação solar global diária incidente estimada (B), no interior do abrigo telado, e deficit de pressão de vapor do ar (DPV) diário, às $15 \mathrm{~h}$, na Estação Meteorológica (C), durante dois experimentos com a cultura da mandioca com plantio em 11/9/2009 (Man1) e 8/9/2010 (Man2). 
meio para controlar o consumo hídrico pela planta e tolerar por mais tempo uma condição de deficit hídrico que, provavelmente, é a abscisão foliar, pois 'Fécula
Branca' apresentou média de queda de folhas ao final do experimento, nas plantas do T2, de 4,4 folhas no Man1 e 4,6 folhas no Man2, enquanto 'Fepagro
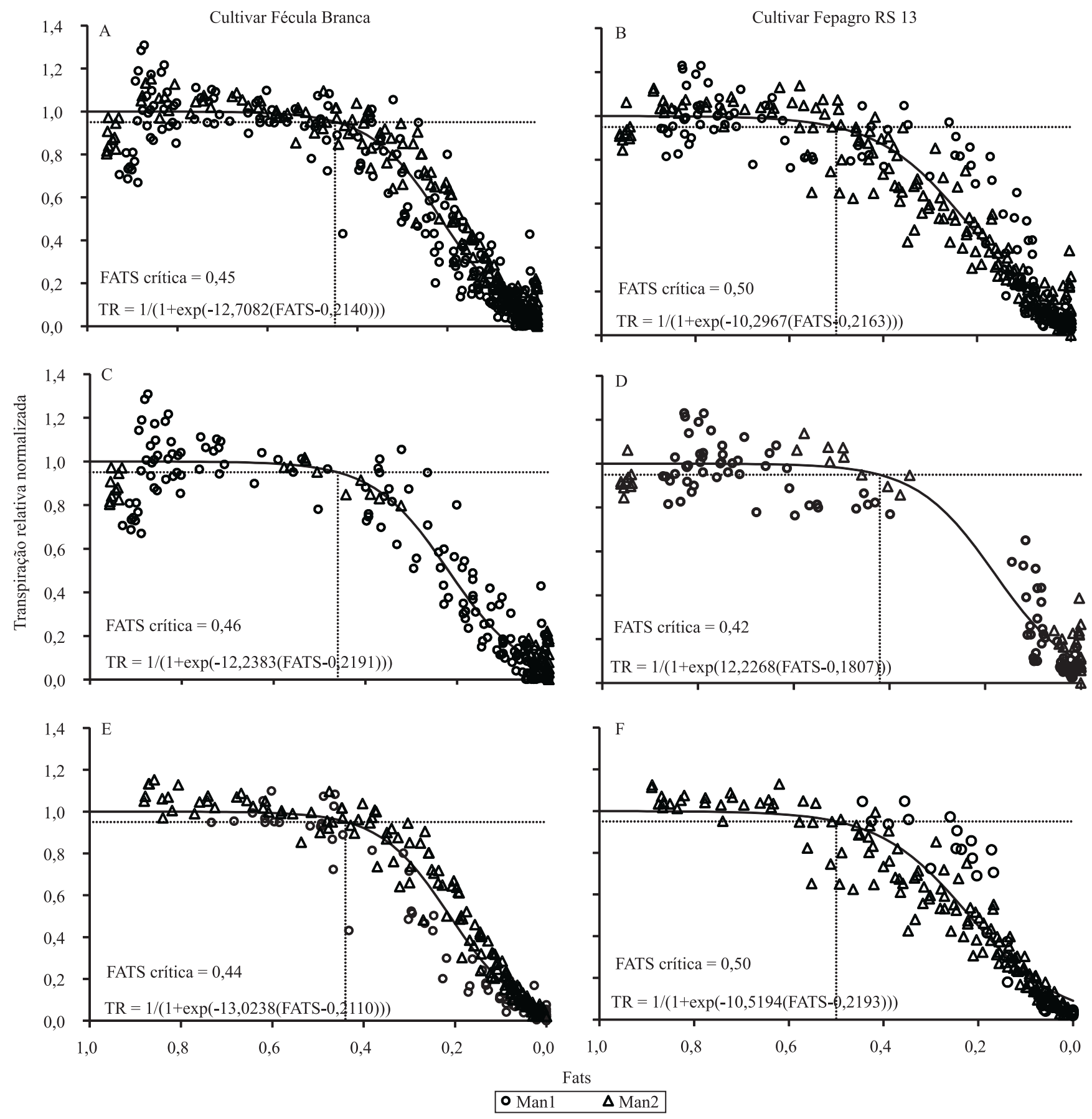

Figura 2. Transpiração relativa normalizada (TR), em função da fração de água transpirável no solo (FATS), para as cultivares de mandioca Fécula Branca e Fepagro RS 13, em abrigo telado, em dois experimentos com data de início da aplicação do deficit hídrico em 19/11/2009 (Man1) e 5/11/2010 (Man2). A e B, dados de todos os dias dos dois experimentos (Man1 e Man2); C e D, dias com deficit de pressão de vapor do ar, às 15:00 h, menor do que $15 \mathrm{hPa}$ nos dois experimentos; E e F, dias com deficit de pressão de vapor do ar, às 15:00 h, maior do que $15 \mathrm{hPa}$ nos dois experimentos. FATS crítica, fração de água transpirável no solo, quando se inicia a redução da transpiração das plantas com o início do fechamento estomático. 
RS 13' apresentou queda de folhas menor (1,2 folhas no Man1 e 2,2 no Man2). Alguns trabalhos com soja (Fletcher et al., 2007), sorgo (Gholipoor et al., 2010) e milheto (Kholová et al., 2010) têm mostrado que há variabilidade genética na resposta da transpiração, em diferentes condições de demanda evaporativa da atmosfera. Essas constatações poderiam explicar a variabilidade, obtida no presente trabalho, entre as
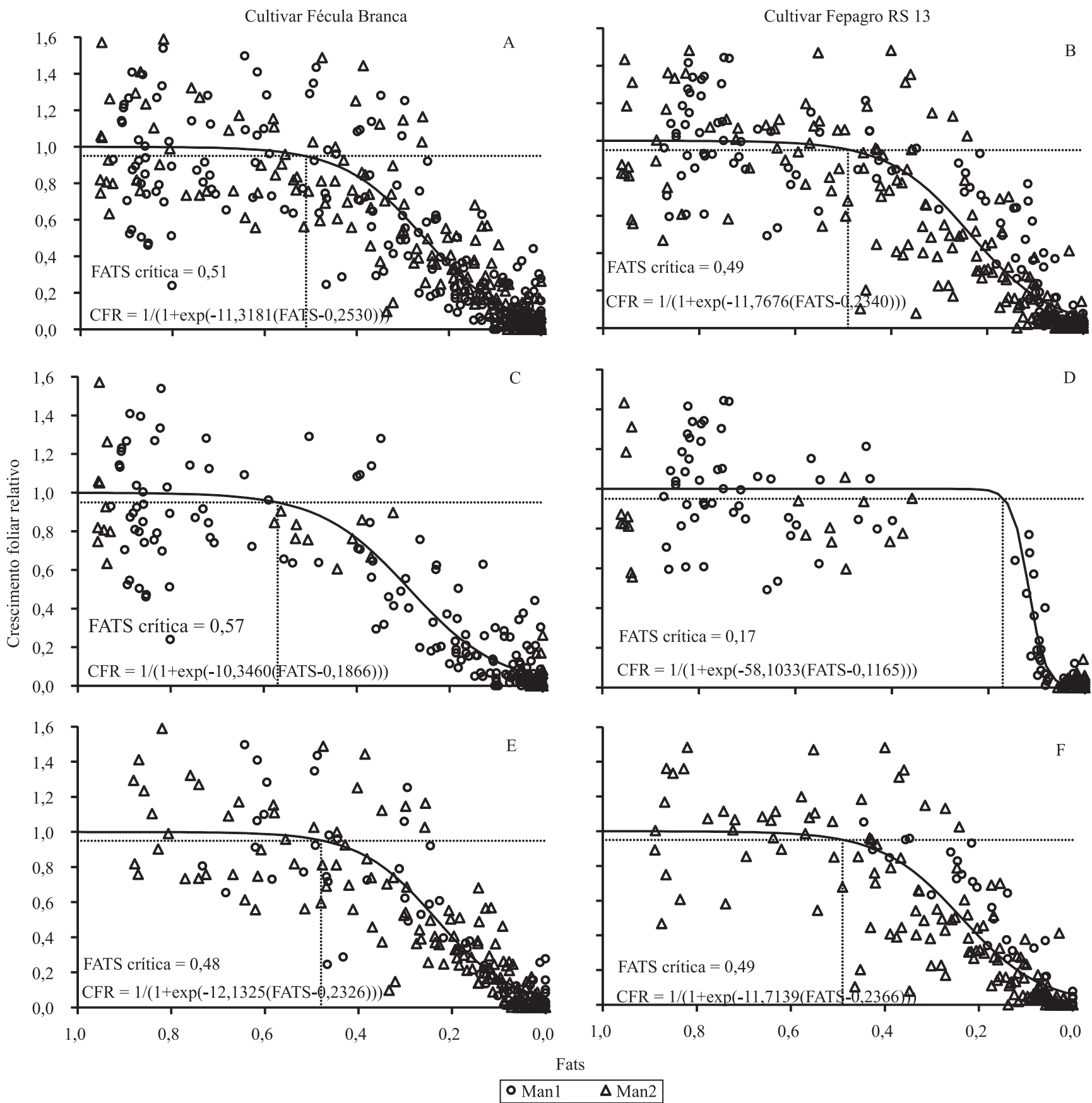

Figura 3. Crescimento foliar relativo normalizado (CFR), em função da fração de água transpirável no solo (FATS), para as cultivares de mandioca Fécula Branca e Fepagro RS 13, em abrigo telado, em dois experimentos com data de início da aplicação do deficit hídrico em 19/11/2009 (Man1) e 5/11/2010 (Man2). A e B, dados de todos os dias dos dois experimentos (Man1 e Man2); C e D, dias com deficit de pressão de vapor do ar, às 15:00 h, menor do que $15 \mathrm{hPa}$ nos dois experimentos; E e F, dias com deficit de pressão de vapor do ar, às 15:00 h, maior do que $15 \mathrm{hPa}$ nos dois experimentos. FATS crítica, fração de água transpirável no solo, quando se inicia a redução do crescimento foliar. 
cultivares de mandioca, quanto aos valores de FATS crítica em que a transpiração começa a ser reduzida.

Ao se analisarem os dados dos dois experimentos conjuntamente, observa-se que o CFR começou a ser reduzido com FATS crítica de 0,51 para 'Fécula Branca' e de 0,49 para 'Fepagro RS 13' (Figura 3), ou seja, valores muito próximos entre as cultivares. Porém, quando se analisam os dados separadamente, em grupos de baixa e de alta demanda evaporativa da atmosfera, observa-se uma grande diferença entre cultivares, em condição de baixa demanda evaporativa da atmosfera, com 'Fepagro RS 13' com FATS crítica bastante baixa $(0,17)$, comparada à 'Fécula Branca' $(0,57)$, enquanto na condição de alta demanda evaporativa, os valores de FATS crítica são próximos: 0,49 e 0,48, respectivamente. $\mathrm{O}$ valor de FATS crítica de 0,17 para CFR deve ser considerado com cautela, em razão da lacuna de pontos existentes na Figura 3 D. Porém, mesmo assim, pode-se observar, pela distribuição dos pontos no gráfico, que a FATS crítica para CFR tende sim a ser menor do que para a TR (Figura 2).

El-Sharkawy et al. (1989), em avaliações em folhas completamente expandidas de várias cultivares de mandioca, em condições ótimas de disponibilidade hídrica e sob deficit hídrico, observaram redução da fotossíntese e da transpiração em DPV acima de valores entre 15 e $20 \mathrm{hPa}$. Esse fato poderia explicar a diferença de FATS crítica entre TR e CFR obtida no presente trabalho. Da mesma forma, El-Sharkawy (1993) observou que a transpiração da mandioca aumenta até valores de DPV próximos de $20 \mathrm{hPa}$ e depois diminui.

A implicação prática desses resultados é que, em condições de alta demanda atmosférica, característica dos dias durante períodos de estiagem na primavera e verão no Rio Grande do Sul, a mandioca tende a fechar os estômatos e reduzir o crescimento das folhas quando a FATS está em torno de 0,5. Quando se compara esse valor com os obtidos para outras culturas agrícolas (Sinclair \& Ludlow, 1986; Amir \& Sinclair, 1991; Muchow \& Sinclair, 1991; Ray \& Sinclair, 1997; Ray et al., 2002; Davatgar et al., 2009), confirma-se que a mandioca tem meio de controle estomático mais eficiente do que a maioria delas (El-Sharkawy et al., 1989; Alves \& Setter, 2000; El-Sharkawy, 2007), o que lhe confere uma posição de destaque como cultura tolerante ao deficit hídrico. Em razão das mudanças climáticas projetadas para o século à frente, no qual eventos extremos como ondas de calor e períodos sem chuva devem se intensificar (Intergovernmental Panel on Climate Change, 2007), e de que a década de 2000 foi caracterizada por uma alta frequência de períodos sem chuva (Streck et al., 2009), a cultura da mandioca tenderá a ganhar destaque pela sustentabilidade, especialmente das pequenas propriedades familiares do Rio Grande do Sul.

Em condições de baixa demanda evaporativa da atmosfera, as duas cultivares de mandioca tiveram respostas diferentes ao deficit hídrico (Figuras 2). A 'Fécula Branca' praticamente não teve resposta quanto ao fechamento estomático e teve pequeno aumento na FATS crítica quanto ao crescimento foliar (Figura 3). A 'Fepagro RS 13' teve valor de FATS crítica menor, especialmente em relação ao crescimento foliar. Quando a demanda evaporativa da atmosfera foi baixa, 'Fepagro RS 13' foi mais eficiente, pois, mesmo com baixa quantidade de água no solo, apresentou evidências de que consegue manter os estômatos abertos, o que permite a entrada de $\mathrm{CO}_{2}$ na câmara subestomática. Já a 'Fécula Branca' reduz a abertura estomática, mesmo em baixa demanda atmosférica, fato que reduz o influxo de $\mathrm{CO}_{2}$ na folha. Essas respostas diferentes entre as cultivares confirmam a variabilidade genética disponível na cultura da mandioca quanto a esses caracteres.

\section{Conclusões}

1. A fração de água transpirável no solo em que a transpiração começa a ser reduzida - FATS crítica - é maior para 'Fepagro RS 13' do que para 'Fécula Branca', enquanto que, para o crescimento foliar, ela é similar para as duas cultivares.

2. O valor de FATS crítica para transpiração e crescimento foliar difere em condições de atmosfera com baixa e com alta demanda evaporativa, conforme a cultivar de mandioca utilizada.

\section{Referências}

ALBERTO, C.M.; STRECK, N.A.; HELDWEIN, A.B.; BURIOL, G.A.; MEDEIROS, S.L.P. Água no solo e rendimento do trigo, soja e milho associados ao El Niño Oscilação Sul. Pesquisa Agropecuária Brasileira, v.41, p.1067-1075, 2006.

ALVES, A.A.C. Cassava botany and physiology. In: HILLOCKS, R.J.; THRESH, J.M.; BELLOTTI, A.C. (Ed.). Cassava: biology, production and utilization. Wallingford: CABI, 2002. p.67-89.

ALVES, A.A.C.; SETTER, T.L. Response of cassava leaf area expansion to water deficit: cell proliferation, cell expansion and delayed development. Annals of Botany, v.94, p.605-613, 2004. 
ALVES, A.A.C.; SETTER, T.L. Response of cassava to water deficit: leaf area growth and abscisic acid. Crop Science, v.40, p.131-137, 2000.

AMIR, J.; SINCLAIR, T.R. A model of water limitation on spring wheat growth and yield. Field Crops Research, v.28, p.59-69, 1991.

AZEVEDO, E.B. de; NÖRNBERG, J.L.; KESSLER, J.D.; BRÜNING, G.; DAVID, D.B. de; FALKENBERG, J.R.; CHIELLE, Z.G. Silagem da parte aérea de cultivares de mandioca. Ciência Rural, v.36, p.1902-1908, 2006.

DAVATGAR, N.; NEISHABOURI, M.R.; SEPASKHAH, A.R.; SOLTANI, A. Physiological and morphological responses of rice (Oryza sativa L.) to varying water stress management strategies. International Journal of Plant Production, v.3, p.19-32, 2009.

EL-SHARKAWY, M.A. Drought-tolerant cassava for Africa, Asia, and Latin America: breeding projects work to stabilize productivity without increasing pressures on limited natural resources. BioScience, v.43, p.441-451, 1993.

EL-SHARKAWY, M.A. Physiological characteristics of cassava tolerance to prolonged drought in the tropics: implications for breeding cultivars adapted to seasonally dry and semiarid environments. Brazilian Journal of Plant Physiology, v.19, p.257-286, 2007.

EL-SHARKAWY,M.A.;COCK,J.H.;PORTO,M.C.M.Características fotossintéticas da mandioca (Manihot esculenta Crantz). Revista Brasileira de Fisiologia Vegetal, v.1, p.143-154, 1989.

FLETCHER, A.L.; SINCLAIR, T.R.; ALLEN JUNIOR, L.H. Transpiration responses to vapor pressure deficit in well watered 'slow-wilting' and commercial soybean. Environmental and Experimental Botany, v.61, p.145-151, 2007.

FOOD AND AGRICULTURE ORGANIZATION OF THE UNITED NATIONS. Production: crops. Available at: $<\mathrm{http}: / /$ faostat.fao.org/site/339/default.aspx>. Accessed on: 16 Sept. 2011.

GHOLIPOOR, M.; VARA PRASAD, P.V.; MUTAVA, R.N.; SINCLAIR, T.R. Genetic variability of transpiration response to vapor pressure deficit among sorghum genotypes. Field Crops Research, v.119, p.85-90, 2010.

INTERGOVERNMENTAL PANEL ON CLIMATE CHANGE. Climate change 2007: the physical science basis: contribution of Working Group I to the Fourth Assessment Report of the Intergovernmental Panel on Climate Change. Cambridge: Cambridge University, 2007. 996p.

JYOSTNA DEVI, M.; SINCLAIR, T.R.; VADEZ, V.; KRISHNAMURTHY, L. Peanut genotypic variation in transpiration efficiency and decreased transpiration during progressive soil drying. Field Crops Research, v.114, p.280-285, 2009.

KHOLOVÁ, J.; HASH, C.T.; KUMAR, P.L.; YADAV, R.S.; KOČOVÁ, M.; VADEZ, V. Terminal drought-tolerant pearl millet [Pennisetum glaucum (L.) R. Br.] have high leaf ABA and limit transpiration at high vapour pressure deficit. Journal of Experimental Botany, v.61, p.1431-1440, 2010.
KINIRY, J.R.; LANDIVAR, J.A.; WITT, M.; GERIK, T.J.; CAVERO, J.; WADE, L.J. Radiation-use efficiency response to vapor pressure deficit for maize and sorghum. Field Crops Research, v.56, p.265-270, 1998.

MATTHEWS, R.B.; HUNT, L.A. GUMCAS: a model describing the growth of cassava (Manihot esculenta L. Crantz). Field Crops Research, v.36, p.69-84, 1994.

MORENO-FONCECA, L.P. Respuesta de las plantas al estrés por deficit hídrico: una revisión. Agronomía Colombiana, v.27, p.179-191, 2009.

MUCHOW, R.C.; SINCLAIR, T.R. Water deficit effects on maize yields modeled under current and "greenhouse climates". Agronomy Journal, v.83, p.1052-1059, 1991.

RAY, J.D.; GESCH, R.W.; SINCLAIR, T.R.; ALLEN, L.H. The effect of vapor pressure deficit on maize transpiration response to a drying soil. Plant and Soil, v.239, p.113-121, 2002.

RAY, J.D.; SINCLAIR, T.R. Stomatal closure of maize hybrids in response to drying soil. Crop Science, v.37, p.803-807, 1997.

SANTOS, H.G. dos; JACOMINE, P.K.T.; ANJOS, L.H.C. dos; OLIVEIRA, V.A. de; OLIVEIRA, J.B. de; COELHO, M.R.; LUMBRERAS, J.F.; CUNHA, T.J.F. (Ed.). Sistema brasileiro de classificação de solos. 2.ed. Rio de Janeiro: Embrapa Solos, 2006. $306 \mathrm{p}$.

SAS INSTITUTE. Statistical Analysis System: user's guide. Version 8.0. Cary: SAS Institute, 2001. 255p.

SCHONS, A.; STRECK, N.A.; KRAULICH, B.; PINHEIRO, D.G.; ZANON, A.J. Emissão de folhas e início de acumulação de amido em raízes de uma variedade de mandioca em função da época de plantio. Ciência Rural, v.37, p.1586-1592, 2007.

SCHONS, A.; STRECK, N.A.; STORCK, L.; BURIOL, G.A.; ZANON, A.J.; PINHEIRO, D.G.; KRAULICH, B. Arranjos de plantas de mandioca e milho em cultivo solteiro e consorciado: crescimento, desenvolvimento e produtividade. Bragantia, v.68, p.155-167, 2009.

SINCLAIR, T.R.; LUDLOW, M.M. Influence of soil water supply on the plant water balance of four tropical grain legumes. Australian Journal of Plant Physiology, v.13, p.329-340, 1986.

SINCLAIR, T.R.; ZWIENIECKI, M.A.; HOLBROOK, N.M. Low leaf hydraulic conductance associated with drought tolerance in soybean. Physiologia Plantarum, v.132, p.446-451, 2008.

STRECK, N.A.; BURIOL, G.A.; HELDWEIN, A.B.; GABRIEL, L.F.; PAULA, G.M. de. Associação da variabilidade da precipitação pluvial em Santa Maria com a Oscilação Decadal do Pacífico. Pesquisa Agropecuária Brasileira, v.44, p.1553-1561, 2009.

TAIZ, L.; ZEIGER, E. Fisiologia vegetal. 4.ed. Porto Alegre: Artmed, 2009. 848p.

WHERLEY, B.G.; SINCLAIR, T.R. Differential sensitivity of $\mathrm{C} 3$ and C4 turfgrass species to increasing atmospheric vapor pressure deficit. Environmental and Experimental Botany, v.67, p.372-376, 2009.

Recebido em 24 de março de 2011 e aprovado em 3 de outubro de 2011 